УДК 532.517

\title{
ПОЛЕ ШВИДКОСТІ ТА ВИХРОВИЙ РУХ УСЕРЕДИНІ НАПІВЦИЛІНДРИЧНОÏ ТРАНШЕЇ
}

\author{
Воскобійник В.А., доктор техн. наук, Воскобійник А.В., канд. техн. наук \\ Інститут гідромеханіки НАН Украӥни, вул. Желябова, 8/4, Київ, 03680, Україна
}

\begin{abstract}
Представлено результати експериментальних досліджень особливостей формування та розвитку когерентних вихрових структур у напівциліндричній траншеї, а також статистичні характеристики поля швидкостей. Визначено масштаби, місцезнаходження когерентних вихрових структур усередині траншеї. Показано вплив вихрового руху в заглибленні на примежовий шар над пласкою поверхнею 3 локальною напівциліндричною траншеєю.
\end{abstract}

Бібл. 15, рис. 4.

\begin{abstract}
Представлены результаты экспериментальных исследований особенностей формирования и развития когерентных вихревых структур в полуцилиндрической траншее, а также статистические характеристики поля скоростей. Определены масштабы, местоположение когерентных вихревых структур внутри траншеи. Показано влияние вихревого движения в углублении на пограничный слой над плоской поверхностью с локальной полуцилиндрической траншеей.
\end{abstract}

The experimental research results of the features of formation and development of the coherent vortical structures in the half-cylindrical trench and also statistical characteristics of velocity field are submitted. The scales and location of the coherent vortical structures inside of the trench are determined. The influence of the vortex motion in the cavity on a boundary layer above a flat surface with the local half-cylindrical trench is shown.

Ключові слова: поле швидкості, вихрова структура, напівциліндрична траншея.

$d$ - діаметр траншеї;

$f$ - частота;

$h$ - глибина траншеї;

$h / d$ - заглиблення траншеї;

$l$ - довжина траншеї;

$P(\omega)$ - спектральна густина потужності пульсацій швидкості;

$R$ - радіус траншеї;

$U_{0}$ - швидкість потоку;

$U$ - осереднена поздовжня швидкість;

$u^{\prime}$ - пульсації поздовжньої швидкості;

$x, y, z$ - осі декартової системи координат;

$\operatorname{Re}_{d}=U_{0} d / v$ та $\operatorname{Re}_{X}=U_{0} X / v-$ числа Рейнольдса;

\section{Bcmyn}

Зі зменшенням кількості корисних копалин і зростанням їх ціни у енергозберігаючих технологіях, де використовується рух рідини або газу чи в них переміщуються різноманітні тіла, набувають широкого використання обтічні лункові поверхні. Вони мають унікальні гідродинамічні властивості, такі як зменшені гідравлічні витрати,
$S t=f d / U_{0}-$ число Струхаля;

$\delta$ - товщина примежового шару перед передньою стінкою траншеї;

$v$ - коефіцієнт кінематичної в'язкості води;

$\sigma-$ дисперсія;

$\omega=2 \pi f-$ кругова частота.

\section{Індекси верхні:}

* - нормування спектрів і частот.

\section{Індекси нижні:}

$d$ - діаметр траншеї;

$X$ - відстань від носка пластини до передньої стінки траншеї.

виникнення флуктуючого вихору в заглибленні, перевищення теплообміну над гідравлічними витратами і деякі інші. Ці властивості використано з користю в різних галузях науки і техніки, таких як ядерна енергетика, теплообмінні системи, в тому числі в комунальній теплоенергетиці, газотурбінні установки та апарати для плавання і польотів [1-3]. Основний фізичний механізм дії 
заглиблень на потік, що їх обтікає - це генерація вихрових структур усередині лунок і викид їх у зовнішню течію. Когерентні вихрові структури суттєво впливають на розвиток примежового шару, відривних течій, процесів змішування i тепломасопереносу. Проблеми визначення просторово-часових характеристик когерентних структур, полів швидкості та тиску в локальних лункових генераторах вихорів, ідентифікації вихрових структур, вивчення механізмів їх генерації та еволюції актуальні не тільки в академічних дослідженнях, але й на практиці під час створення сучасних транспортних засобів та інтенсифікації процесів змішування й тепломасопереносу [1-3]. Заглиблення на поверхні, яке обтікається рідиною, є джерелом звукових і псевдозвукових коливань (останні з яких обумовлені переносом когерентних вихрових структур) [4, 5]. Генерація коливальних тонів течією над видовженою траншеєю - це відоме явище, яке має місце в колісних сховищах та бомбових люках в літаках, щілинах на дверцятах автомобілів, технічних нішах в корпусах суден. Рівні звукового і псевдозвукового тиску бувають такими високими, що спричиняють до шумових проблем всередині літаків, підводних човнів та автомобілів і руйнують делікатні інструменти та устаткування в самих канавках. Основна особливість течій в канавках чи кавернах $є$ формування зсувного шару, який підсилює збурення потоку і наступне трансформування цих збурень в акустичні хвилі на кормовій стінці канавки [6]. Акустичні хвилі переносяться проти течії до передньої стінки канавки. Тут в зоні відриву примежового шару та зародження зсувного шару ці хвилі призводять до формування областей нестійкості, які викликають подальші збурення в зсувному шарі. Таким чином, замикається петля зворотного зв'язку, яка породжує автоколивання на дискретних резонансних частотах $[4,6,7]$.

Історично вивчення автоколивань почалося 3 дослідження крайових тонів, при яких струмінь виходив 3 отвору та ударявся об гострий край. Механізм розвитку та формування крайових тонів схожий до механізму для кавітаційних коливань, про який згадувалося раніше: збурення підсилюються в зсувному шарі і трансформуються в акустичні хвилі, які виникають на гострому краю. Акустичні хвилі породжують подальшу нестабільність зсувного шару, замикаючи, таким чином, петлю зворотного зв'язку. Крайові тони це канонічна проблема, яка характеризує розповсюдження звуку в повітропровідних музичних інструментах, таких як флейта або органні трубі і які близько відносяться до течій в видовженій канавці. Перший опис явища акустичного резонансу, який пов'язаний з коливаннями усередині канавок, належить Розіт'єру [8]. Він запровадив напівемпіричну формулу, яка дає можливість знайти частоти автоколивань.

У видовжених прямокутних заглибленнях існує також інша мода коливань, до якої привернуто менше уваги і яка через це менше вивчена. В дослідах 3 нестисливою рідиною для вісесиметричної канавки в роботі [9] виявили слідну моду, за якою осцилююча течія над каверною нагадує слід за погано обтічним тілом. Слідна мода пов'язується зі значним збільшенням опору. Коли довжина прямокутної канавки зростає відносно товщини примежового шару на передньому краю заглиблення виникають коливання рідини, які підпорядковуються принципу біфуркації. Ці коливання змінюються від моди зсувного шару (для коротких каверн) до слідної моди (для видовжених канавок). Особливості течії при слідній моді якісно відрізняються від тих, що мають місце при моді зсувного шару, які досліджував Розіт'єр.

Вивченню структури вихрової течії в поперечно обтічній напівциліндричній траншеї присвячена дана робота. Мета цієї роботи - отримати кінематичні характеристики вихрової течії у траншеї та у примежовому шарі обтічної поверхні поблизу траншеї, а також знайти характерні частоти коливального процесу як у самій траншеї, так і поблизу неї.

\section{Експериментальна установка}

Експериментальні роботи проводились на аеродинамічному стенді в Інституті гідромеханіки НАН України $[10,11]$. Стенд був створений на базі аеродинамічної труби відкритого типу. Робоча ділянка труби мала циліндричну форму 3 внутрішнім діаметром 0,1 м та була зроблена 3 прозорої труби для проведення візуальних дослідів. Повітря 3 лабораторного 
приміщення поступало до труби через конфузорний вхід у вигляді лемніскати Бернулі для зменшення збурення потоку та створення прийнятного ступеня турбулентності в аеродинамічній трубі. На виході з робочої ділянки труби стояв центробіжний насос, який всмоктував повітря через аеродинамічну трубу. Між робочою ділянкою і насосом знаходився проміжний гумовий циліндр для зменшення вібраційних перешкод від насоса. Рівні звукового тиску та вібрацій в робочій ділянці труби контролювались при проведені дослідів. Під час створення стенду віброакустичні шуми були виміряні й прийнята низка заходів по їх зменшенню і усуненню.

В діаметральній площині аеродинамічної труби в напрямку іiі поздовжньої вісі встановлювалась пласка пластина 3 локальним заглибленням у вигляді напівциліндричної траншеї, яка обтікалась потоком. Пластина виготовлена 3 листа товщиною $4 \cdot 10^{-3} \mathrm{M}$, який був підсилений ребрами жорсткості 3 нижньої неробочої сторони пластини. Ширина пластини складала 0,1 м, а довжина - 0,6 м. Передній i кормовий краї пластини були загострені для того, щоб усунути зони відриву примежового шару. На відстані 0,5 м від початку пластини було зроблено отвір, в якому розташовувалася напівциліндрична канавка. Канавка мала діаметр $20 \cdot 10^{-3}$ м та довжину $80 \cdot 10^{-3}$ м і обтікалась поперечним, відносно іiі повздовжньої вісі потоком. Швидкість потоку в дослідах змінювалась від 1 м/с до 20 м/с, що давало можливість дослідити ламінарний та турбулентний режими обтікання гідравлічно гладкої пласкої поверхні пластини 3 локальним заглибленням. Для цих режимів течії числа Рейнольдса розраховані за швидкістю потоку та діаметром траншеї або відстанню від носка пластини до передньої стінки траншеї складали відповідно $\operatorname{Re}_{d}=(1,4 \ldots 24,6) \times 10^{3} \quad$ i $\quad \operatorname{Re}_{X}=(3,7 \ldots 67) \times 10^{4}$. Інтенсивність турбулентності набігаючого потоку за межами примежового шару над пластиною не перевищувала $3 \%$.

Поле швидкості над обтічною поверхнею та усередині траншеї вимірювалось за допомогою однониткового дротяного датчика, який підключався до мостової електричної схеми термоанемометра постійної температури фірми Діза. Координатний пристрій дозволяв пересувати датчик 3 точністю $10 \cdot 10^{-6}$ м в трьох взаємно перпендикулярних напрямках. Контроль місцезнаходження датчика відносно обтічної поверхні проводився за допомогою лазерної установки.

Електричні сигнали від датчиків подавались на контрольно-вимірювальну апаратуру (вольтметри, осцилоскопи, частотоміри) i апаратуру реєстрації даних (чотирьохканальний вимірювальний магнітофон фірми Брюль i К'єр). Зареєстровані електричні сигнали оброблялись на спеціалізованих спектроаналізуючих комплексах та через аналогово-цифрові перетворювачі подавались на персональні комп'ютери. На комп'ютерах, за розробленими програмами та методиками, дані оброблялись i аналізувались. За допомогою відповідного програмного забезпечення та графічних редакторів результати досліджень перетворювались у відповідні залежності.

Дротяні термоанемометри калібрувались та тестувались перед проведенням дослідів, під час дослідів, а також після закінчення робіт. Це давало можливість отримувати калібровочні залежності параметрів, які реєструються датчиками, що було використано під час обробки та аналізу експериментальних результатів.

Похибка під час вимірювання інтегральних та осереднених значень кінематичних характеристик вихрової течії у траншеї та над пластиною не перевищувала $10 \%$ достовірністю 0,95 або 2 б. Спектральні характеристики поля пульсацій швидкості вимірювались $з$ похибкою не більше 2 дБ у частотному діапазоні від 0,2 Гц до 1250 Гц.

Окрім інструментальних дослідів проводились візуальні дослідження за допомогою димової візуалізації. Джерело диму знаходилось на поверхні пластини перед траншеєю. Картини візуалізації реєструвались за допомогою швидкісних кінокамер, відеокамер та цифрових фотоапаратів. Відео та фотоматеріал візуалізації 3 застосуванням відповідних програм та методик фіксувався на персональних комп'ютерах, де оброблявся і аналізувався. Похибка оцінки геометричних і кінематичних характеристик вихрового потоку та структури течії у траншеї та над пласкою пластиною не перевищувала (15...20)\%. 


\section{Результати досліджень ї̈х аналіз}

Під час проведення експериментальних досліджень були отримані осереднені та пульсаційні характеристики поля швидкості над обтічною поверхнею пластини і усередині напівциліндричної траншеї в іiї поперечному серединному перетині. На рис. 1 наведені профілі осередненої поздовжньої швидкості в траншеї та над пластиною, які отримані для ламінарного та турбулентного режиму течії. Дані отримано завдяки статистичній обробці результатів

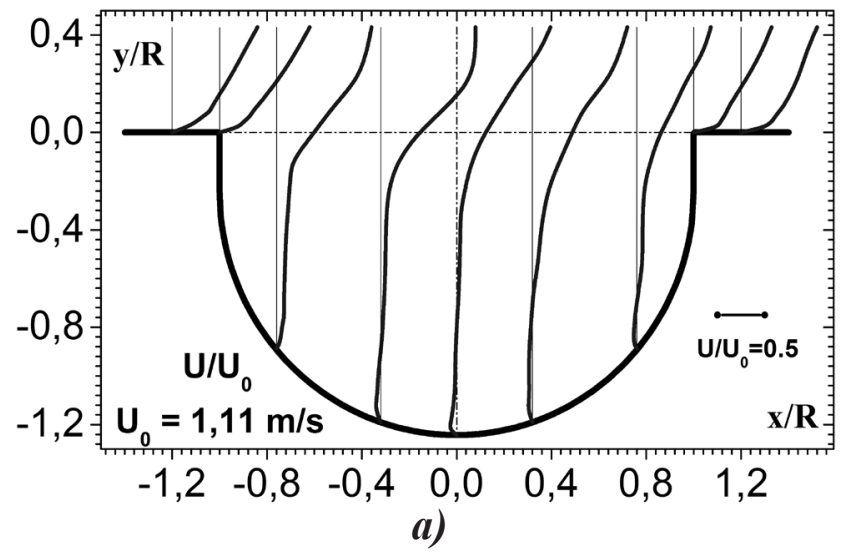

вимірювання швидкостей на протязі однієї хвилини реєстрації даних. На рис. 1, $a$ результати отримано для швидкості потоку $1,11 \mathrm{~m} / \mathrm{c}$, якому відповідають числа Рейнольдса $\mathrm{Re}_{d}=1360$ та $\mathrm{Re}_{X}=37000$. На рис. 1, $\sigma$ результати наведено для $U_{0}=20,1 \mathrm{~m} / \mathrm{c}, \operatorname{Re}_{d}=24600$ та $\operatorname{Re}_{X}=670000$. На цьому рисунку крива 1 відповідає даним Афанасьєва та ін. [12], які отримані для мілкої напівциліндричної канавки, а крива 2 - це результати даного дослідження.

Як показують результати досліджень, 3

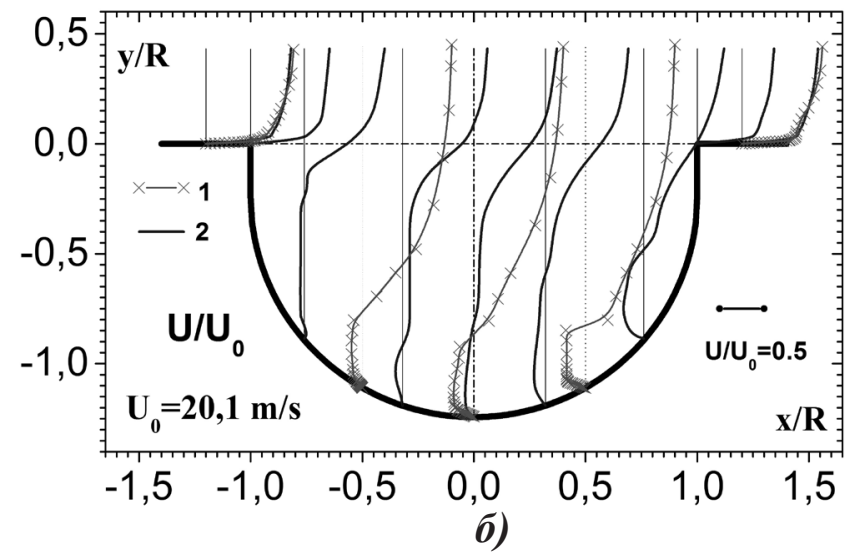

Рис. 1. Профілі осередненої поздовжньої швидкості усередині та над напівциліндричною траншеєю для ламінарної (а) і турбулентної (б) течії.

заглибленням в траншею має місце зниження середньої поздовжньої швидкості. В перерізі, яке знаходиться нижче середини траншеї, виокремлюється зона нульових значень поздовжньої осередненої швидкості. 3 наближенням до дна траншеї з'являється область зворотної течії, напрямок якої протилежний набігаючому потоку. Для ламінарного режиму зворотній потік майже непомітний, але зі збільшенням швидкості він стає все інтенсивнішим. При цьому зона зворотного потоку наближається від придонної області траншеї до іiі серединної частини (рис. 1, a та рис. 1, б). Таким чином, для турбулентного режиму усередині траншеї зареєстровано великомасштабну циркуляційну течію, центр якої знаходиться між геометричною серединою канавки та іiі дном. Такий циркуляційний рух рідини в траншеї напівциліндричної форми спостерігається як у представлених дослідах, так і в роботі [12]. Необхідно зазначити, що розташування центру циркуляційної течії в цих двох дослідах загалом співпадає. Значення швидкостей на периферії циркуляційної течії, які показано на рис. 1, б, для двох умов досліджень мають розходження тому, що геометричні параметри траншеї в цих дослідах не співпадають.

Середньоквадратичні значення пульсацій поздовжньої швидкості ростуть у пристінній області примежових шарів над обтічною пластиною та усередині напівциліндричною траншеї, там, де спостерігається максимальна дія сил в'язкості. Крім того пульсації поздовжньої швидкості ростуть 3 наближенням до кормової стінки траншеї. Тут має місце найбільш нестійка взаємодія примежового шару, що формується над пластиною, з вихровими структурами зсувного шару та 3 великомасштабною вихровою системою, яка генерується усередині траншеї й викидається з неї назовні $[13,14]$. Поблизу цієї області відбувається інтенсивна взаємодія вихрових структур зсувного шару з кормовою стінкою 
поперечно обтічної траншеї та зароджується циркуляційна течія. Мінімальні значення пульсацій поздовжньої швидкості реєструються у тих місцях, де спостерігається зміна напрямку вектора осередненої швидкості, а саме в ядрі квазістійкого великомасштабного вихору, що формується усередині траншеї. Над кормовою стінкою траншеї пульсації поздовжньої швидкості суттєво перевищують значення, які фіксуються над передньою стінкою. Як показали досліди, зі збільшенням швидкості ця різниця збільшується.

Окрім осереднених швидкостей та їх пульсацій в поздовжньому напрямку були отримані і поперечні швидкості, що дало мо-

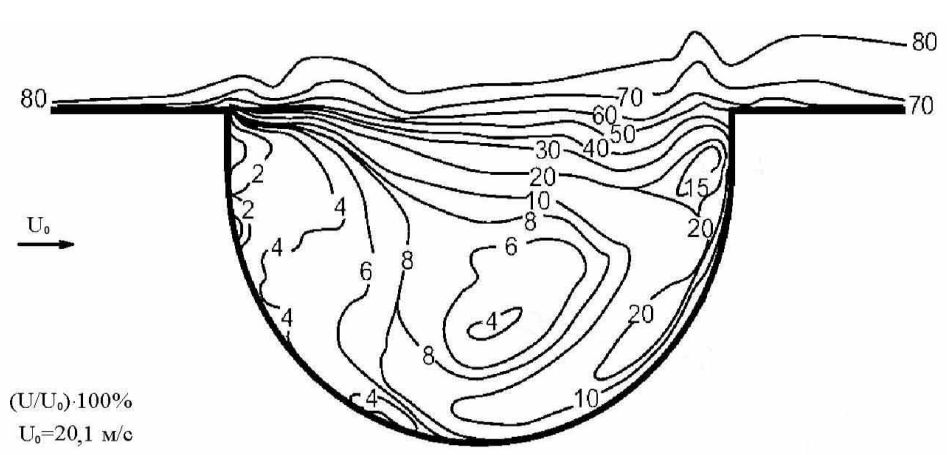

a) жливість побудувати векторні поля швидкості у заглибленні та поза ним. Побудовані ізотахи або лінії рівних осереднених швидкостей, які визначають кінематичні характеристики вихрового руху в траншеї та біля неї показано на рис. 2, $a$, a їх середньоквадратичні значення пульсацій представлено на рис. 2, б. Ці лінії рівних швидкостей отримано для швидкості $20 \mathrm{~m} / \mathrm{c}$ і чисел Рейнольдса таких самих, як і для даних наведених на рис. 1, б. Цифри на ізолініях на рис. 2, a позначають середню швидкість відносно швидкості набігаючого потоку у відсотках. На рис. 2, б середньоквадратичні значення пульсації швидкості також нормовані швидкістю потоку.

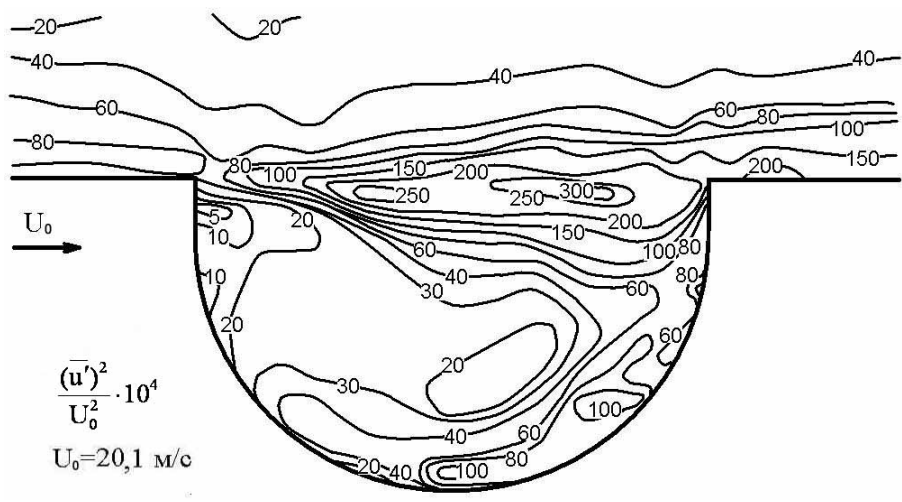

б)

Рис. 2. Ізотахи осереднених швидкостей (а) та їх середньоквадратичних значень пульсацій (б) усередині та над напівциліндричною траншеєю, щңо обтікається турбулентним потоком.

У примежовому шарі, який утворюється над гідравлічно гладкою поверхнею пластини, 3'являються зони гальмування та прискорення, що обумовлено дією на нього заглиблення, зокрема вихровою течією, що має місце усередині заглиблення. Під час відриву примежового шару зароджується зсувний шар, який має хвилеподібну форму (наприклад, рис. $2, a$ ), що обумовлено прискоренням та гальмуванням потоку усередині і назовні канавки, а також формуванням в ньому вихрових систем. Цей зсувний шар розширяється під час просування вздовж отвору канавки і з підходом його до кормової стінки він взаємодіє з останньою. При цьому одна частина зсувного шару пересувається на вихід із траншеї, гальмуючи рідину, яка рухається над поверхнею заглиблення, що проілюстровано на рис. 2, $a$. Інша частина зсувного шару, який взаємодіє $з$ кормовою стінкою, прямує вздовж дна траншеї до іiі переднього краю. Цей струменеподібний пристінний потік, перетинаючи середину траншеї підіймається до зсувного шару, подібно результатам, які спостерігав Роквелл [15] для прямокутного заглиблення. Струменеподібний потік та нижня частина зсувного шару в отворі заглиблення формують циркуляційну течію у вигляді великомасштабного квазістійкого вихору. Великомасштабна когерентна вихрова структура розташовується в нижній придонній частині траншеї і займає майже третину іï об’єму (подібно спостереженням Роквелла). В місці взаємодії зсувного шару 3 кормовою стінкою реєструються дрібномасштабні, але 
високоенергійні вихрові структури, які конвектують із зсувним шаром. Нижче зони відриву примежового шару та формування зсувного шару біля передньої стінки і місця підйому струменеподібного потоку зароджується система дрібномасштабних когерентних вихрових структур малої енергії. Із зменшенням швидкості набігаючого потоку число, місцезнаходження та масштаб квазістійких вихрових структур змінюється. Так, їх число зменшується, а розмір великомасштабного когерентного вихору збільшується і він переміщується ближче до центру заглиблення та до його передньої стінки.

Як показують результати досліджень, в області ядер вихрових систем пульсації швидкості незначні, а на їх периферії - великі (рис. 2, б). Особливо великі рівні пульсацій швидкості спостерігаються в місцях зародження зсувного шару та в області його взаємодії 3 кормовою стінкою. Подібні тенденції формування поля пульсацій швидкості спостерігались як для ламінарного, так і турбулентного режимів обтікання пластини 3 локальним заглибленням [10].

Спектральні характеристики поля пульсацій повздовжньої швидкості, зареєстрованої на рівні поверхні отвору напівциліндичної канавки в іiі серединному перетині показано на рис. 3. Тут зображено залежності спектральних густин потужностей пульсацій швидкості, які нормовані зовнішніми змінними $\delta$ та $U_{0}$, а саме ( $\left.P^{*}(\omega)=P(\omega) \delta /\left[\left(\overline{u^{\prime}}\right)^{2} \cdot U_{0}\right]\right)$ від частоти $\left(\omega^{*}=\omega \delta / U_{0}\right)$ для швидкості $U_{0}=20,1 \mathrm{~m} / \mathrm{c}$ і чисел Рейнольдса $\operatorname{Re}_{d}=2,46 \times 10^{4}$ та $\operatorname{Re}_{X}=6,7 \times 10^{5}$. На цьому рисунку цифрами позначено криві, які відповідають різним координатам точок заміру швидкостей вздовж отвору траншеї $(x / R)$. Відомо, що таке представлення спектральних залежностей дає можливість оцінити як інтенсивність пульсацій швидкості, так і їх частотне наповнення. Так, площі під спектральними кривими дорівнюють середнім значенням квадратів пульсацій поздовжньої швидкості віднесених до квадратів швидкості потоку.

Як показують результати досліджень, над передньою частиною отвору траншеї спектрам пульсацій поздовжньої швидкості притаманний монотонно змінний характер. Спектри мають конвективний гребінь, який є характерною ознакою спектральних залежностей поля пульсацій швидкості або тиску у турбулентному примежовому шарі над гідравлічно гладкою поверхнею. 3 наближенням до серединної частини траншеї в спектрах з'являються добре помітні дискретні складові, частоти та інтенсивність яких обумовлені дією вихрових структур, що генеруються усередині траншеї та викидаються назовні $з$ неї (криві 4...8 на рис. 3 ).

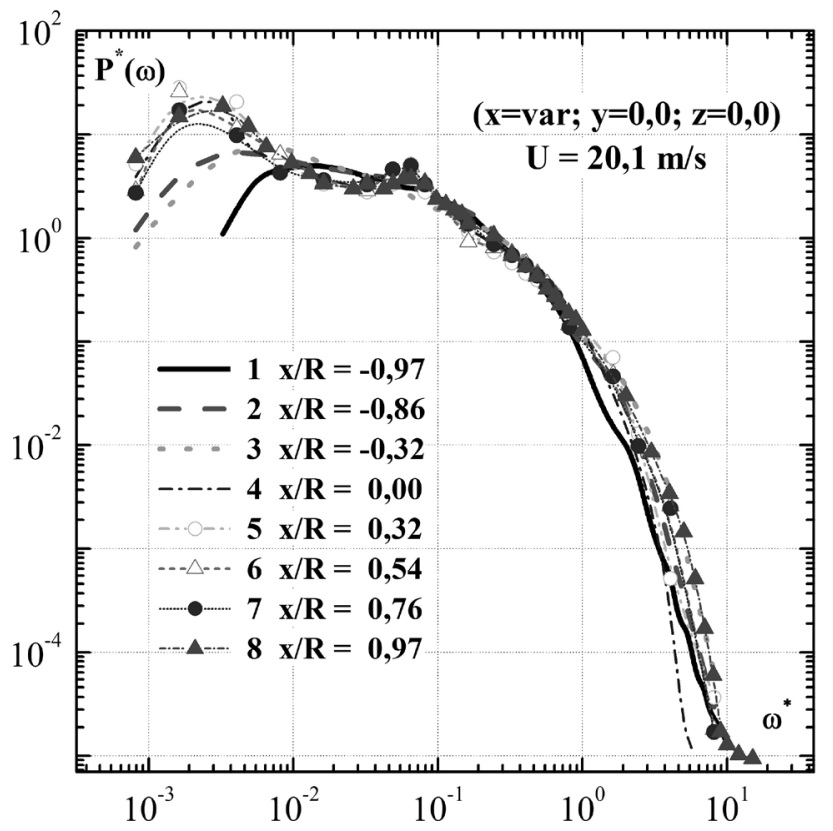

Рис. 3. Спектральні густини потужнності пульсацій поздовжньої швидкості для серединного перетину напівциліндичної траншеї.

Згідно з рекомендаціями Бредшоу для більшої наглядності визначення домінуючих спектральних компонент використовуються перші моменти спектрів. На рис. 4 показано перші моменти спектральних густин потужностей пульсацій поздовжньої швидкості у вигляді $\omega P(\omega)$ в залежності від $\omega^{*}$ для тих же умов обтікання i координат розташування термоанемометричних датчиків, що й на рис. 3. Рис. 4 дає можливість оцінити вклад кожної частотної компоненти в загальну енергію поля пульсацій швидкості.

Установлено, що поблизу передньої стінки траншеї спектральні залежності мають монотонно змінний характер (криві 1, 2 та 3). 3 наближенням до серединної частини траншеї, де 
струменеподібна пристінна течія підіймається до зсувного шару і взаємодіє 3 ним (рис. 2), в спектрах з'являються характерні особливості у вигляді дискретних піків. Ці піки спостерігаються від середини заглиблення і до його кормової стінки, що проілюстровано як на рис. 3 , та і на рис. 4. Піки зосереджено в низькочастотному діапазоні $0.002<\omega^{*}<0.003$, якому відповідають частоти $f=(2 \ldots 4)$ Гц, та $0.05<\omega^{*}<0.08$ або $f=(60 \ldots 90)$ Гц. Подібні дискретні піки у відповідних частотних діапазонах спостерігались в середині напівциліндичної траншеї, де зароджувались квазістікі великомасштабні когерентні вихрові системи [10]. 3 віддаленням від передньої відривної стінки траншеї спектри наповнюються високочастотними компонентами, які обумовлено дією дрібномасштабних вихорів на поле пульсацій швидкості. Поблизу кормової стінки напівциліндичної траншеї з'являється ще один дискретний пік, який добре видно на рис. 4 , що відповідає частотам $0.5<\omega^{*}<0.7$ або $f=(600 \ldots 800)$ Гц.

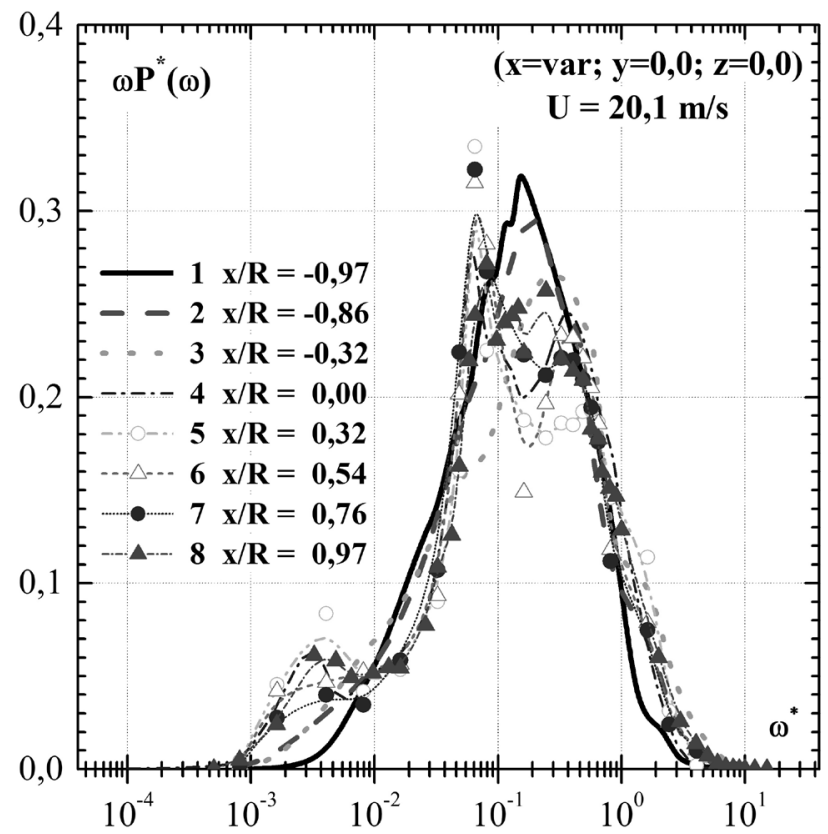

Рис. 4. Перші моменти спектрів пульсацій поздовжньої ивидкості для серединного перетину напівциліндричної траншеї.

Таким чином, над серединною та кормовою частинами траншеї на рівні поверхні обтічної пластини спостерігаються характерні особливості в спектральних залежностях пульсацій швидкості, які притаманні вихровому руху усередині заглиблення. Ці характерні особливості проявляються, зокрема, в появі дискретних піків в трьох частотних діапазонах. Перший діапазон $\omega^{*}=(0.002 \ldots 0.003)$ обумовлений низькочастотним коливанням вихрового руху усередині поперечно обтічної траншеї, головним чином, вздовж іiі поздовжньої осі. Другий діапазон частот $\omega^{*}=(0.05 \ldots 0.08)$ відповідає викидам великомасштабної вихрової системи або iii частини назовні із траншеї, що підтвердилося під час аналізу візуалізації вихрової течії. Масштаб цієї квазістійкої вихрової структури для турбулентної течії над траншеєю оцінюється, як $0.3 d$. Циркуляція великомасштабної когерентної вихрової структури, нормована зовнішніми змінними (швидкістю потоку та радіусом траншеї) складає 0.18. Дискретний пік у третьому частотному діапазоні обумовлений взаємодією вихрових структур зсувного шару 3 кормовою стінкою канавки. При цьому в заглибленні формуються автоколивання i вони відповідають другій зсувній моді Розіт'єра коливань усередині траншеї. Цим коливанням відповідає число Струхаля $S t=f d / U_{0}=0.64$. Отже, на рівні поверхні обтічної пластини в районі $-0.32<x / R<0$ починається викид вихрових систем або їх частин із траншеї у примежовий шар 3 частотою біля $(60 \ldots 90)$ Гц для $U_{0}=20 \mathrm{~m} / \mathrm{c}$ та чисел Рейнольдса $\mathrm{Re}_{X}=6,7 \times 10^{5} \mathrm{i}$ $\mathrm{Re}_{d}=2,46 \times 10^{4}$.

\section{Висновки}

Результати експериментальних досліджень інтегральних і спектральних залежностей поля швидкості усередині та поблизу поперечно обтічної напівциліндичної траншеї, яку розташовано на гідравлічно гладкій плоскій поверхні, показали, що

1. За характером зміни ліній рівних осереднених швидкостей та їх пульсацій, визначених із статистичного аналізу даних, витікає, що усередині траншеї генеруються квазістікі великомасштабні когерентні вихрові структури та дрібномасштабні вихори, число яких збільшується 3 ростом швидкості потоку. Масштаб, місце розташування та форма великомас- 
штабних вихорів змінюються в залежності від режиму течії, що викликає зміни в полі швидкості усередині траншеї й поблизу неї.

2. Установлено, що загальними закономірностями зміни інтегральних характеристик поля швидкості є: по-перше, наявність областей збільшення та зменшення значень поздовжньої швидкості над траншеєю, які чередуються між собою, обумовлені дією вихрових структур, що генеруються усередині траншеї, на примежовий шар; по-друге, збільшення середньої швидкості та іiі пульсацій $з$ наближенням зсувного шару до кормової стінки траншеї; по-третє, поява в придонній області траншеї оберненої течії у вигляді пристінного струменя, яка зароджується в зоні взаємодії вихрових структур зсувного шару 3 кормовою стінкою траншеї.

3. Визначено, що статистичні моменти вищих порядків розподілення поля пульсацій поздовжньої швидкості зазнають суттєвих змін усередині траншеї та в іiї ближньому сліді відносно значень, які притаманні для турбулентних примежових шарів над гідравлічно гладкими плоскими поверхнями. В спектральних залежностях з'являються дискретні складові, які відповідають характерним низькочастотним коливанням вихрового руху усередині траншеї, частоти яких складають число Струхаля порядку 0,003. Зокрема, в спектрах превалюють складові на частотах викидів великомасштабних вихрових структур, що зароджуються усередині траншеї, назовні у примежовий шар, яким відповідає число Струхаля (0.05...0.08), а також на частоті, яку обумовлено другою зсувною модою автоколивань вихрових структур $\mathrm{St} \approx 0.6$.

\section{ЛІТЕРАТУРА}

1. Управление обтеканием тел с вихревыми ячейками в приложении к летательным аппаратам интегральной компоновки (численное и физическое моделирование) / Под ред. А. В. Ермишина и С. А. Исаева. - М.: СПб., 2001. - 360 с.

2. Халатов A.А. Теплообмен и гидродинамика около поверхностных углублений (лунок). К.: ИТТФ НАНУ, 2005. - 76 c.

3. Гортышиов Ю.Ф., Попов И.А., Олимпиев B.В., Щелчков А.В., Каськов С.И. Теплогидравлическая эффективность перспективных способов интенсификации теплоотдачи в каналах теплообменного оборудования. - Казань: Центр инновационных технологий, 2009. - 531 с.

4. Воскобійник B. А. Просторово-часові характеристики когерентних структур, полів швидкості та тиску у лункових генераторах вихорів: Автореф. дис. д. т. н.: 01.02.05 - механіка рідини, газу та плазми. / Інститут гідромеханіки НАН України. - Київ, 2013. - 40 с.

5. Voskoboinick V., Kornev N., Turnow J. Study of near wall coherent flow structures on dimpled surfaces using unsteady pressure measurements // Flow Turbulence Combust. - 2013. - Vol. 90, No. 4. - P. 709 - 722.

6. Lin J. - C., Rockwell D. Organized oscillations of initially turbulent flow past a cavity // AIAA J. 2001. - 39, No. 6. - P. 1139 - 1151.

7. Cabell R. H., Kegerise M. A., Cox D. E., Gibbs G. P. Experimental feedback control of flow induced cavity tones // AIAA Pap. - 2002. No. 2497. - P. 1 - 10.

8. Rossiter J.E. Wind-tunnel experiments on the flow over rectangular cavities at subsonic and transonic speeds // Aeronautical Research Council. 1964. - Rep. Mem. No. 3438. - P. 1 - 36.

9. Gharib M., Roshko A. The effect of flow oscillations on cavity drag // J. Fluid Mech. - 1987. - Vol. 177. - P. 501 - 530.

10. Воскобойник В.А., Воскобойник А.В. Пульсации скорости внутри поперечно обтекаемого полуцилиндрического углубления // Вісник Донецького Університету, Сер. А: Природничі науки. - 2012. - Вип. 2. - С. $25-30$.

11. Турик В.М., Воскобійник В.А., Воскобійник $A . B$. Вплив напівциліндричної канавки на інтегральні характеристики примежового шару над пластиною // Вісник НТУУ „КПІ”: Машинобудування. - 2012. - Вип. 64. - С. 47 - 55.

12. Афанасьев В.Н., Веселкин В.Ю., Леонтьев А.И. $u \partial p$. Гидродинамика и теплообмен при обтекании одиночных углублений на исходно гладкой поверхности: Препринт МГТУ им. Н.Э. Баумана № 2-91. Ч. 1. - М.: Изд-во МГТУ, 1991. - 56 с.

13. Воскобойник В.А., Воскобойник А.В. Циркуляційна течія у поперечно обтічній напівциліндричній траншеї // Вісник Донецького Університету, Сер. А: Природничі науки. - 2012. - Вип. 1. - С. 45 - 50. 
14. Турик В.Н., Бабенко В.В., Воскобойник В.А., Воскобойник A.B. Вихревое движение в полуцилиндрической канавке на пластине // Промислова гідравліка і пневматика. - 2011. -

\section{VELOCITY FIELD AND VORTEX MOTION INSIDE THE HALF-CYLINDRICAL TRENCH}

\section{Voskoboinick V.A., Voskoboinick A.V.}

Institute of Hydromechanics of the National Academy of Sciences of Ukraine, str. Zhelyabova, 8/4, Kyiv, 03680, Ukraine

The experimental research results of the features of formation and development of the coherent vortical structures in the half-cylindrical trench and also statistical characteristics of velocity field are submitted. The scales and location of the coherent vortical structures inside of the trench are determined. The influence of the vortex motion in the cavity on a boundary layer above a flat surface with the local half-cylindrical trench is shown.

References 15, figures 4.

Key words: velocity field, vortex structure, halfcylindrical trench.

1. Body flow control with vortex cells in supplement to aircraft of integral design (numerical and physical simulation) Ed. A.V. Ermishin and S.A. Isaev. - M.: SPb., 2001. - 360 p. (Rus.)
T. 33, No. 3. - C. $23-27$.

15. Rockwell D. Vortex-body interactions // Annu. Rev. Fluid Mech. - 1998. - Vol. 30. - P. 199 229.

2. Khalatov A.A. Heat transfer and hydrodynamics about surface cavities (dimples). - K.: ITTF NASU, 2005. - 76 p. (Rus.)

3. Gortyschov Yu.F., Popov I.A., Olimpiev V.V., Stchelchkov A.V., Kaskov S.I. Heat-hydraulical efficiency of perspective methods of intensification of heat emission in the channels of heat-exchange equipment. - Kazan: Center of innovative technologies, 2009. - 531 p. (Rus.)

4. Voskoboinick V.A. Space-time characteristics of coherent structures, velocity and pressure fields into the dimpled vortex generators: Thesis doctor degree of engineering sciences by specialty 01.02.05 mechanics of fluid, gas and plasma / Institute of Hydromechanics of NASU, Kyiv, 2013. - 40 p. (Ukr.)

5. Voskoboinick V., Kornev N., Turnow J. Study of near wall coherent flow structures on dimpled surfaces using unsteady pressure measurements // Flow Turbulence Combust. - 2013. - Vol. 90, No. 4. - P. $709-722$.

6. Lin J. - C., Rockwell D. Organized oscillations of initially turbulent flow past a cavity // AIAA J. 2001. - 39, No. 6. - P. 1139 - 1151.

7. Cabell R. H., Kegerise M. A., Cox D. E., Gibbs G. P. Experimental feedback control of 
flow induced cavity tones // AIAA Pap. - 2002. No. 2497. - P. 1 - 10.

8. Rossiter J.E. Wind-tunnel experiments on the flow over rectangular cavities at subsonic and transonic speeds // Aeronautical Research Council. 1964. - Rep. Mem. No. 3438. - P. 1 - 36.

9. Gharib M., Roshko A. The effect of flow oscillations on cavity drag // J. Fluid Mech. - 1987. Vol. 177. - P. 501 - 530.

10. Voskoboinick V.A., Voskoboinick A.V. Velocity fluctuations inside cross-streamlined halfcylindrical cavity // Bulletin of Donetsk University, Series A: Natural Sciences. - 2012. - No. 2. P. 25 - 30. (Rus.)

11. Turick V.N., Voskoboinick V.A., Voskoboinick $A$.V. Influence of half-cylindrical cavity on integral characteristics of wall boundary layer // Bulletin of NTUU “KPI". Mechanical Engineering. - 2012. -
Vol. 64. - P. 47 - 55. (Ukr.)

12. Afanasiev V.N., Veselkin V.Yu., Leontiev A.I. ets. Hydrodynamics and heat transfer by stream of single cavities on unconfigured state smooth surface. No. 2-91, pt. 1. - M.: MGTU, 1991. - 56 p. (Rus.)

13. Voskoboinick V. A., Voskoboinick A. V. Circulation flow in the cross-streamlined halfcylindrical trench // Bulletin of Donetsk University, Series A: Natural Sciences. - 2012. - No. 1. - P. 4550. (Ukr.)

14. Turick V. N., Babenko V. V., Voskoboinick V. A., Voskoboinick $A . V$. Vortex motion in the halfcylindrical cavity on a plate // Industrial Hydraulics and Pneumatics. - 2011. - Vol. 33, No. 3. - P. 23 27. (Rus.)

15. Rockwell D. Vortex-body interactions // Annu. Rev. Fluid Mech. - 1998. - Vol. 30. - P. 199 229.

Получено 29.05.2014 Received 29.05.2014 